\title{
Fault Diagnosis Simulation Model Study of Wind Turbine Drive Train Based on SIMULINK
}

\author{
Xianjiang Shi ${ }^{\mathrm{a}}$, Heng Du ${ }^{\mathrm{d}}$, Jingchun Zhang ${ }^{\mathrm{b}}$, Jiankun Zhang ${ }^{\mathrm{c}}$, Junshan $\mathrm{Si}^{\mathrm{e}}$ \\ School of Mechanical and Power Engineering, Harbin University of Science and Technology, \\ Harbin 150080, Chain \\ ahustsxj@hrbust.edu.cn, ${ }^{b}$ duheng1228@126.com, ${ }^{\text {jjingchunbulibuqi@163.com, }{ }^{d} z j k z z a @ 126 . c o m, ~}$ \\ esijunshan@sina.com
}

Keyword: Wind Turbine generator; Drive system; Gear; Stator voltage; Fault diagnosis, SIMULINK

\begin{abstract}
In order to study the response characteristics of the wind turbine drive system gear fault in its electrical signal in the stator theoretically, on the basis of considering the gear mesh stiffness change and simulating the broken gear fault characteristics, building the gear vibration dynamics differential equation and the simulation model. The induction motor model provided by SIMULINK is set as winding generator mode, simulate doubly-fed wind power generator. Connect the speed fluctuations output of the gear vibration model with the speed input of the generator model, construct electrical and mechanical joint simulation model. Through simulation and verification analysis, it shows that the generator electrical signals can accurately reflect the mechanical fault characteristics information of the transmission system.
\end{abstract}

\section{Introduction}

Motor current signal analysis method, which is currently used in fault diagnosis of motor and drive equipment. In recent years, in the generator, especially in wind turbines aspects there have research reports. Such as Royo [2], Wen Xian Yang [2] and Xing Gong [2] and Amirat [5, 6], using the stator electrical signal to diagnose generator broken bars, bearings and other mechanical fault diagnosis, achieving good results. However, most of the existing literature aim at the generator itself, electrical or mechanical failure, transmission (eg gearbox) fault diagnosis researches which have higher failure rate are rarely reported. In this paper, take the common gear of double-fed wind turbine transmission chain as objects, ,joint generator electrical simulation model and mechanical dynamics model of gear transmission system, through simulation analysis and experimental verification of the stator voltage signal, study the feasibility and effectiveness of this method.

\section{Mechanical Model of a Wind Turbine Drive Gear}

By the literature [7], as shown in figure 1, dynamics differential equation of spur gear transmission vice is:

$$
M_{r} \ddot{x}+C \dot{x}+k(t) x=k(t) E_{1}+k(t) E(t)
$$

In the formula: $\mathrm{x}$ is relative displacement along the line of action of the gear; $\mathrm{C}$ is the gear damper; $\mathrm{k}$ (t) is a gear mesh stiffness; $M r$ is the equivalent mass of the two gear, $M_{r}=\frac{m_{1} m_{2}}{m_{1}+m_{2}} \mathrm{E} 1$ is average static elastic deformation of gear after the gear get loading; E2 ( $\mathrm{t}$ ) is equal to relative displacement between the two gears which is caused by the error and fault of the gear.

By the excitation function at right end of formula (1), it can be seen that the vibration of the gear derive from two parts: Part is K (t) E1, it has nothing to do with the errors and failures of gears, so it 
is called conventional vibration, which can be considered as 0 at the ideal state, then the equation (6) is reduced to:

$$
M_{r} \ddot{x}+C \dot{x}+k(t) x=k(t) E_{2}(t)
$$

At the moment, the exciting force is only $\mathrm{K}(\mathrm{t}) \mathrm{E}_{2}(\mathrm{t})$, which is a modulated signal. It depends on the composite stiffness of gear and the change process of the fault function. Figure 3 is a change curve of the spur gear meshing stiffness $\mathrm{K}(\mathrm{t})$, it can be approximated regard as a square wave function at the ideal state; $E_{2}(t)$ depends on the type of gear failures, If gear appears broken teeth failure, $E_{2}(t)$ appears at the frequency of the gear periodically, We can say that the vibration of the gear is dominantly caused by $\mathrm{K}(\mathrm{t})$ and $\mathrm{E}_{2}(\mathrm{t})$ modulation which is a periodic change.

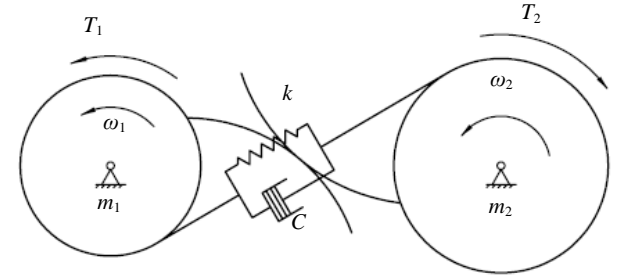

Fig. 1 The mechanical model of Generator drive gears

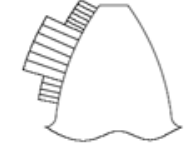

(a) Tooth surface load

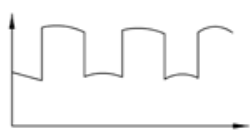

(b) Mesh stiffness

Fig.2 Tooth surface load and stiffness changes

\section{Wind Turbine Drive Gear Vice Simulation Model}

According to the vibration differential equation (6), we can obtain corresponding output displacement response as long as make appropriate secondary output acceleration integral. The basic module library of SIMULINK can be used to establish simulation model, as shown in Figure 4. Because the generator model simulation requires angular velocity input, extracting velocity parameters of the model, divided by the radius of the gear as the angular velocity output. The main parameters of the gear system: The number of teeth of the large gear and the pinion gear $Z_{1}=32$, $Z_{2}=23$, Face width B is 20 , the calculated mass $M_{r}=40 \mathrm{~kg}$ When considering the quality of the motor, $k=7 \mathrm{kN}, C=200 \mathrm{~N} \mathrm{~s} / \mathrm{m}$. In simulating, $\mathrm{fz}$ is input gear mesh frequency, which is equal to the changeable frequency of meshing stiffness; Fr1 is rotating frequency of input fault gear shaft.

\section{The Simulation Model of Doubly-fed Wind Power Generator Which Including Gear Transmission Deputy}

Doubly-fed generator simulation model directly using induction motor module in SIMULINK, it is set as induction motor Generator operation mode. Other generator rotor frequency excitation module, Load module, electrical parameter measurement module are calling SIMULINK library components. Synthesize gear fault simulation module which is shown in Figure 2 into a child module. Superimpose its outputs with an average rotational speed, input to the input terminal of the generator speed. Because the output of gear fault simulation sub-module is only a component of velocity fluctuations, it needs to add the average speed values.

The basic parameters of the simulation system are: Rated power of generator is $3 \mathrm{~kW}$, Number of pole pairs p is 2, Stator resistance, inductance Rs $=1.9188 \Omega$, Ls $=0.24122 \mathrm{H}$, converted to the stator side rotor resistance, inductance $\mathrm{Rr}=2.5712 \Omega, \mathrm{Lr}=0.24122 \mathrm{H}$, stator and rotor mutual inductance $\mathrm{Lm}=0.234 \mathrm{H}$. Take synchronization reference coordinate system as the reference coordinate system, the initial states is zero. 


\section{Wind turbine fault simulation test bench}

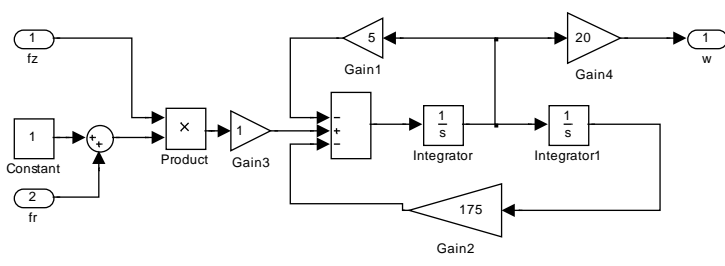

Fig.3 The mechanical simulation model of Generator drive gears

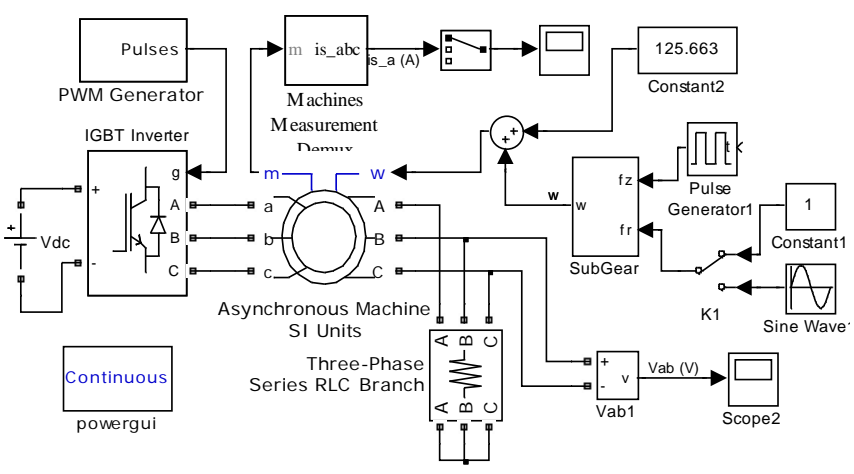

Fig.4 Doubly-fed induction generator and control system simulation model

In order to verify the simulation results, we establish a wind turbine fault simulation experiment platform, the overall structure of diagram simulation test bench is shown in Figure 5, the fan simulating motor adopt AC asynchronous motor, variable frequency drive; Doubly-fed induction generator adopt a wound three-phase asynchronous motor, which is connected to the generator mode, the inverter gives variable frequency excitation to the rotor. Gear pair are adopted to simulate wind turbine growth box, the number of large gear teeth $\mathrm{z}_{1}=23$ in the motor end, the number of pinion gear teeth $\mathrm{z}_{2}=34$ in the generator end, the growth rate is about 1.478.
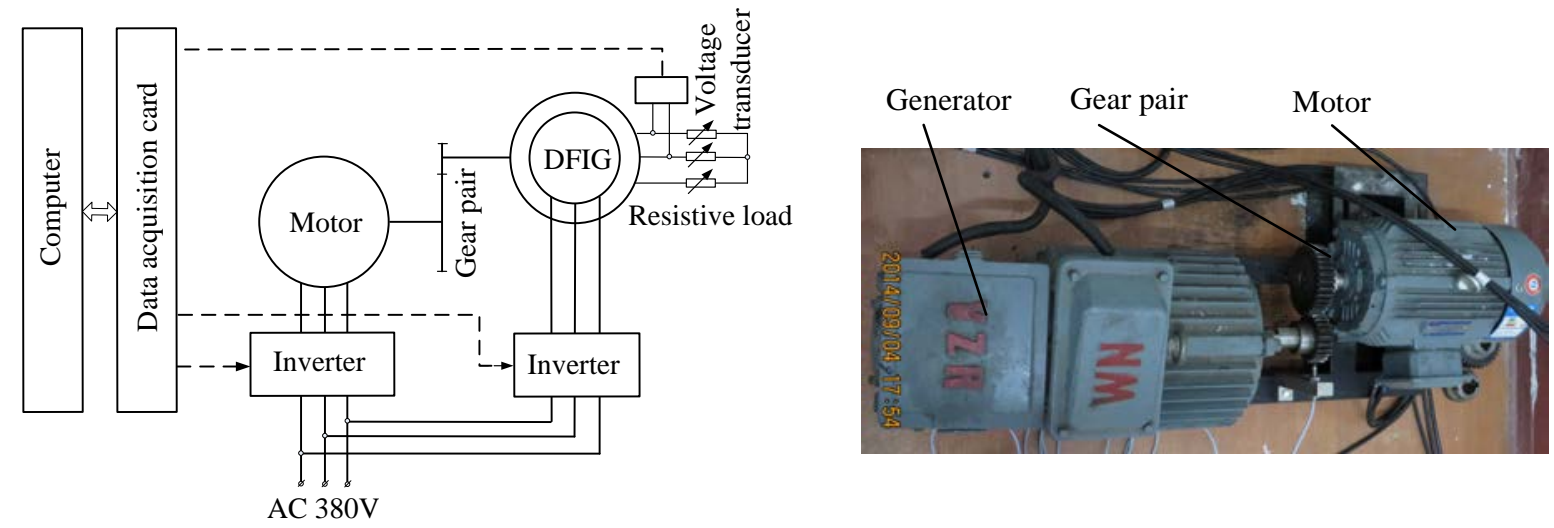

(a) Control system diagram

(b) Test bed photos

Fig. 5 Wind turbine gear fault simulation test bench and the control

\section{The results of simulation and analysis of gear fault}

When the manual switch K1 in Fig. 4 turn to constant 1 , which equal the $E_{2}(t)$ in type (2) is a constant value, that means incentive system is only concerned with $K(t)$, system is fault free and at normal state. During the simulation, the average speed of rotor is $w_{r 2}=47.124 \mathrm{rad} / \mathrm{s}$, rotor power frequency $f_{2}=35 \mathrm{~Hz}$, power frequency is about $50 \mathrm{~Hz}$ at the moment. There are no other obvious frequency components (Graphics skip) except the $50 \mathrm{~Hz}$ frequency component in the calculated signal spectra of stator voltage.

When the manual switch K1 in Fig. 4 turn to the harmonic signal input, we can simulate local fault of gear. Only set the fault frequency is the rotational frequency, such as the big gear $f_{r 1}=3 \mathrm{~Hz}$, the stator voltage spectrum as shown in figure 6 at the moment. Modulate the power frequency with sideband composition in power frequency $(50.27 \mathrm{~Hz})$ of the amplitude spectrum, we can clearly obtain $2.81 \mathrm{~Hz}$ component of rotation speed fluctuation in instantaneous frequency demodulation, which illustrates that in the off grid conditions, speed fluctuation caused by Tooth Breaking failure 
mainly lead to power frequency produce fluctuations, and the fluctuation frequency and fault simulation have the same frequency.

\section{The simulation experiment platform of gear fault verification}

Simulate and verify the experiment in the test platform as shown in figure 6. During the test, the power supply voltage of the generator rotor is $100 \mathrm{~V}$, and frequency is $35 \mathrm{~Hz}$; the motor stator power frequency is $10 \mathrm{~Hz}$, the measured spectrum of generator stator side phase voltage signal shown in figure 9. We can see the corresponding large gear shaft and pinion shaft rotational frequency is $2.91 \mathrm{~Hz}$ and $4.61 \mathrm{~Hz} .4 .61 \mathrm{~Hz}$ is the rotation frequency of the generator shaft, which may be associated with the failure of the shaft balancing or misalignment; $2.91 \mathrm{~Hz}$ is wind axle rotating frequency, it is certainly caused by simulation of large gear of the shaft of the broken teeth faults.

\section{Conclusion}

Through comparative analysis of the theoretical simulation and experimental results, theoretical simulation and simulation test results are basically identical. But the test bench experimental results is much richer than simulation, it is proved that the simulation model is available, But it can describe the fault information is unitary .In addition, it show that the generator electrical signal can accurately reflect the mechanical fault feature information, and mechanical failure information appears mainly in the form of frequency modulation,

It indicates that in the off grid environment, fluctuating phenomenon happens in the generator frequency of generator.

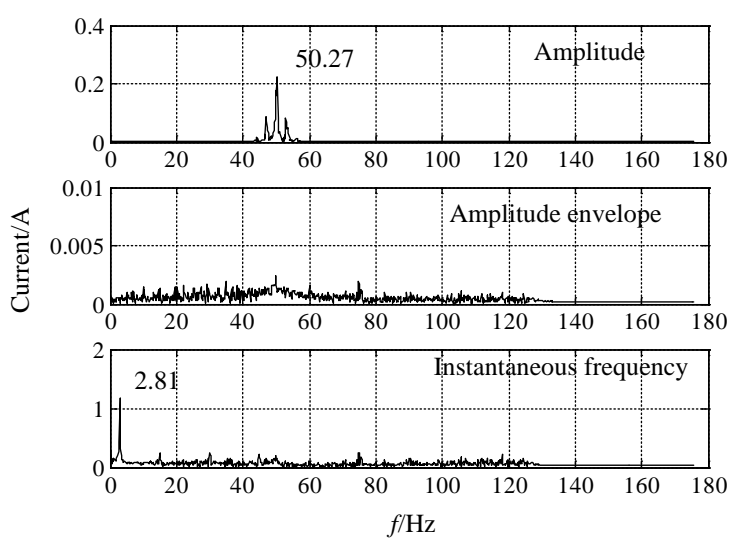

Fig. 6 The spectrum of generator stator current when simulate fault

$\left(f_{2}=10 \mathrm{~Hz}, \omega_{r 2}=47.124 \mathrm{rad} / \mathrm{s}, f_{r 1}=3 \mathrm{~Hz}\right)$

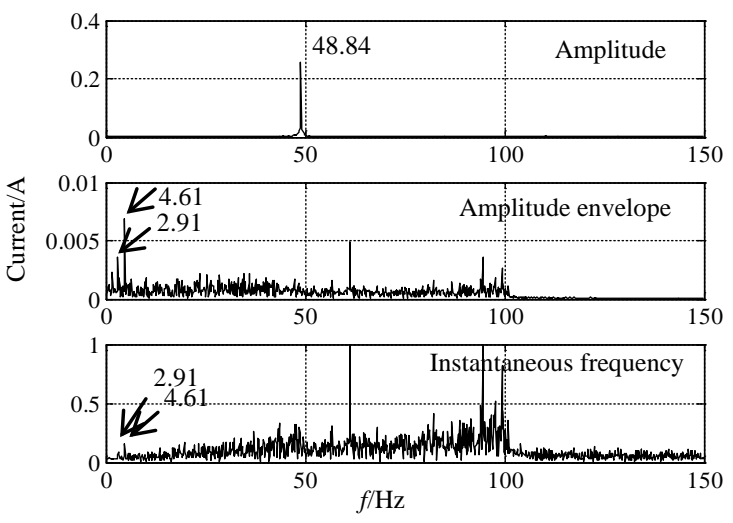

Fig. 7 The generator stator current signal Spectrum when simulate broken teeth fault $\left(f_{2}=10 \mathrm{~Hz}\right.$, Power frequency of motor is $35 \mathrm{~Hz}$ )

\section{Acknowledgment}

This article is funded by the national natural science foundation of China (51275136).

\section{References}

[1] Yanxia Shen, Fa Li: Control Engineering of China, Vol.20, No. 3(2013), pp.789.(in Chinese)

[2] Xuefeng Chen , Jimeng Li, Hang Cheng, et al. : Journal of Mechanical Engineering, Vol.47, No. 9(2011), pp.45.(in Chinese)

[3] Wenxian Yang, Tavner P. J. and Crabtree C.J., et al. :IEEE Transaction on Industrial Electronics, Vol. 57, No. 1(2010), pp. 2631. 
[4] Xiang Gong, Wei Qiao, Wei Zhou. Incipient Bearing Fault Detection via Wind Generator Stator Current and Wavelet Filter, in: Proceedings -IECON 2010, 36th Annual Conference of the IEEE Industrial Electronics Society, (2010), pp.2615.

[5] Amirat Y., Choqueuse V. and Benbouzid M.E.H., et al. Bearing Fault Detection in DFIG-Based Wind Turbines Using the First Intrinsic Mode Function, in: 19th International Conference on Electrical Machines-ICEM 2010,(2010),pp.1.

[6] Xingwu Wang, Zhaoya Zhang, Yongli Wu. Computer Simulation, Vol. 26, No. 10(2009), pp. 294. (in Chinese)

[7] Ruilin Wang, Da Xie, Xitian Wang, et. al. Electrical Automation, Vol.33, No. 1(2011),pp. 51. (in Chinese)

[8] Xianjiang Shi, Hua Guo, Junpeng Shao. Journal of Vibration, Measurement \& Diagnosis, Vol.29, No. 3(2009), pp. 352. (in Chinese) 